\title{
A promising route of magnetic based materials for removal of cadmium and methylene blue from waste water
}

\author{
M. Ruthiraan ${ }^{\mathrm{a}}$, E.C. Abdullah ${ }^{\mathrm{a}, *}$, N.M. Mubarak $^{\mathrm{b}, * *}$, M.N. Noraini $^{\mathrm{a}}$ \\ a Malaysia-Japan International Institute of Technology (MJIIT), Universiti Teknologi Malaysia, Jalan Semarak, 54100 Kuala Lumpur, Malaysia \\ ${ }^{\mathrm{b}}$ Department of Chemical Engineering, Faculty of Engineering and Science, Curtin University, 98009 Sarawak, Malaysia
}

\section{A R T I C L E I N F O}

\section{Article history:}

Received 20 October 2016

Received in revised form 13 December 2016

Accepted 25 February 2017

Available online 27 February 2017

\section{Keywords:}

Magnetic biochar

Methylene blue dye

Mangosteen peel

Muffle furnace

Cadmium

Iron oxide

\section{A B S T R A C T}

Adsorption equilibrium is an essential measure to be controlled in attaining the maximum capacity of an adsorbent. Synthesis of magnetic biochar by using various discarded biomass possesses varied adsorbate adsorption capability. Maximising the removal percentage of the pollutant from wastewater by altering operational parameters are the very important skill to be mastered by environmentalist. In this research work, mangosteen peel derived ferric oxide magnetic biochar was pyrolysed at $800^{\circ} \mathrm{C}$ for 20 min via modified muffle furnace at zero oxygen environment. The factors affecting adsorption were studied for two different liquid pollutant. A comparative study was carried out for adsorption of methylene blue dye and $\mathrm{Cd}$ (II) ions by altering the adsorbate $\mathrm{pH}$, agitation speed, and contact time and particle diffusion mechanism were investigated respectively. The removal of methylene blue dye attained maximum removal at $\mathrm{pH}$ of 7.0 and above, $50 \mathrm{~min}$ contact time and $150 \mathrm{rpm}$ agitation speed. Moreover, adsorption equilibrium of Cd (II) ions reaches maximum removal percentage at the $\mathrm{pH}$ value of 8.0, agitation speed of $150 \mathrm{rpm}$ and $60 \mathrm{~min}$ contact time. The thermodynamics study was performed to further understand the effect of operating temperature in determining the adsorption spontaneous of adsorption medium. The experimental analysis reveals that the produced magnetic biochar is viable for adsorption of both heavy metal ions and organic pollutant at optimised condition.

(c) 2017 Elsevier Ltd. All rights reserved.

\section{Introduction}

Environmental issues have always been a widely faced problem by the entire biosphere including flora and fauna on earth. Water pollution is one of the challenges. Water pollutants are categorised into a few categories such as organic substances like methylene blue dye [1], ammonia [2], phenol [3] and other aromatic compounds that are widely used in textile industries. Besides, heavy metals such as mercury, copper, zinc [4], cadmium [5], stannum [6], nickel, lead and other metals released by metal smelters, steel factories during electrodeposition and electrophoretic coating contribute to wastewaters [7]. Wood preservative [8],

\footnotetext{
* Corresponding author at: Malaysia-Japan International Institute of Technology (MJIIT), Universiti Teknologi Malaysia, Jalan Semarak, 54100 Kuala Lumpur Malaysia. Fax: 8032203126.

** Corresponding author at: Department of Chemical Engineering, Faculty of Engineering and Science, Curtin University, 98009 Sarawak, Malaysia. Fax: 86085 443837.

E-mail addresses: ruthimaran89@gmail.com (M. Ruthiraan), ezzatc@utm.my, ezzatchan@gmail.com (E.C. Abdullah), mubarak.mujawar@curtin.edu.my, mubarak.yaseen@gmail.com (N.M. Mubarak).
}

battery manufacturing [9] and various other chemical manufacturing have increased the concern among the environmentalists regarding the invention of better methodologies for removal of pollutants. One of the consequences of the presence of heavy metals includes serious threats to human beings affecting the central nervous system [10], increased chances of lung cancer [11], mental retardation, gastrointestinal disorder, abdominal pain and a range of other diseases. Heavy metal interrupts food chain and causes risk to the entire ecosystem and living resources.

Various specialised treatments are currently used for the removal of liquid pollutants such as tertiary bio-filtration, cross flow microfiltration, the polymer enhanced ultrafiltration and advanced membrane filtration [12,13]. Besides that, there are certain simple chemical precipitation methods for removal of metals using insoluble hydroxide carbonates or sulphides [8]. Electrochemical deposition is also a widely used method for the removal of heavy metal at the industrial scale. Adsorption is recognised as a low-cost and highly efficient technique among all the above-stated methods for the removal of organic pollutants from wastewater and result into high-quality treated effluent. This most widely used method is employed using different adsorbents such as activated charcoal, activated carbon and biochar. Dyes are a 
type of organic pollutants largely utilised by the textile, pulp, and paper industries. These chemicals are reported to generate considerable quantities of coloured, toxic and even carcinogenic wastewaters, posing a serious threat to aquatic organisms. This water if consumed by animals and human beings can be highly intoxicating. The major reason is the non-biodegradable nature of most of the dyes and resistance to aerobic digestion [14]. Activated carbon as an adsorbent for organic pollutants involves a complex process with considerable difficulty. Dependency on multiple variables such as electrostatic, chemical interactions, intrinsic properties of the solute and adsorbent, solution properties such as $\mathrm{pH}$, and the temperature of the system increases the complexity in monitoring and regulating the process [15]. Therefore, the efficiency in removal of dyes and heavy metal is very low. Heavy metals are naturally occurring elements having a high atomic mass and density, at least, five times greater than that of water. Their application in industries, domestic purposes, agriculture, medicine, and technology have resulted in their widespread distribution in the environment. It has raised concerns regarding their potential effects on human health and the environment. Because of their high degree of toxicity, arsenic, cadmium, chromium, lead, and mercury are the most toxic metals that are of public health significance.

Preparation of activated carbon involves a two-stage production, making the process more time consuming and less efficient. To overcome this problem, a magnetic carbon adsorbent called Magnetic Biochar (MB) is invented. The synthesis of the MB involves a single step using lesser energy and generating less environmental degradation. Moreover, synthesis of this fascinating adsorbent has reduced the post-treatment process. The introduction of metal ions onto the biochar surface through pyrolysis process does not only enhance the pores formation yet create a magnetic effect. The transformation of this bio-adsorbent ease the removal of magnetic biochar upon completion of adsorption process from wastewater by using magnet [16]. Numerous biomass has been used widely to produce various carbon-based adsorbents such as sugarcane bagasse, rice husk, bamboo, mangosteen peel and durian peel. The most easily accessible and abundantly available biomass is viable for mass production of magnetic biochar to be employed at industrial scale [17].

Mangosteen fruit is widely found in several South-east Asian countries especially Malaysia, Thailand and Indonesia. The increasing consumption of mangosteen fruit has given a lead to abundant left mangosteen peel residue whereas $60 \%$ of the fruit is a waste. In a study by Chen, Huang [18], the group investigated effects of the mixing method of $\mathrm{K}_{2} \mathrm{CO}_{3}$ with biomass constituting the peel of Mangosteen fruit. The one-step impregnation of mangosteen peel with $\mathrm{K}_{2} \mathrm{CO}_{3}$ and activation process is more effective for production of activated carbon with greatly improved adsorption capacities (based on methylene blue and iodine adsorption data), higher BET surface area, greater total pore volume, and highly developed mesopores, as compared to the two-stage activation approach of solid-solid mixing. The "L" form of MSAC (mangosteen activated carbon) formed by one-step impregnation exhibits a maximum adsorption capacity of $21.74 \mathrm{mg}$ per gram of adsorbent for copper (II) ions in aqueous solution. The spent L-MSAC if treated with $\mathrm{H}_{2} \mathrm{SO}_{4}$, showed higher recovery and regeneration efficiencies in three adsorptiondesorption cycles. All the studies were done in order to make a useful adsorbent out of waste in Malaysia to fight with the increased waste management cost, such application can be regarded as an important step towards the betterment of present environmental crises. The analysis outcome of the properties and adsorption behaviour of the mangosteen peel based adsorbent has thriven the interest to synthesised mangosteen peel derived magnetic biochar.
In this study, iron oxide impregnated magnetic biochar was synthesised by using electrical muffle furnace at zero oxygen condition. The significant influences of biomass sonication frequency, heating time and temperature on the carbon yield was optimised for batch adsorption study of methylene blue dye and Cd (II) ions. The surface morphology and structural properties of the produced magnetic biochar were characterised. The factors affecting batch adsorption process were determined by manipulating the operational parameters for organic dye and heavy metal ion in aqueous solution. Different types of adsorbate were chosen in this study to govern the adsorption feasibility of the produced magnetic biochar.

\section{Materials and methodology}

\subsection{Raw material}

The collected mangosteen peels from local markets at Penang were thoroughly washed to remove impurities and fungus. The precursor was oven dried at $105^{\circ} \mathrm{C}$ for five days to attain minimal moisture content. The discarded biomass was repeated crushed and sieve to maintain particle size less than $50 \mu \mathrm{m}$. All chemicals used in this study are of analytical grade quality purchased from Friendemann Schmidt and used as received.

\subsection{Synthesis of magnetic biochar}

The impregnation process of biomass was conducted by sonicating the good mixture of $1.0 \mathrm{M} \mathrm{Fe}_{2} \mathrm{O}_{3}$ solution together with grounded mangosteen peel for $5 \mathrm{~h}$ at $40{ }^{\circ} \mathrm{C}$ with $70 \%$ sonicating frequency (model: Elmasonic) by adding $0.4 \mathrm{M}$ of $\mathrm{KMnO}_{4}$ and $\mathrm{HNO}_{3}$ aqueous solution at a ratio of $1: 3$. The suspension was further dried till minimal moist content obtained.

The second stage process involves the pyrolysis of mixed biomass at zero oxygen environment by using a modified Muffle Furnace model WiseTherm, FP-03, $1000^{\circ} \mathrm{C}, 3 \mathrm{~L}$. $50 \mathrm{~g}$ of the welldried mixture was filled in a crucible and the furnace door was closed tightly. The suction pump was connected to the top valve of the furnace to achieve zero oxygen content. The suction was continued until the suction pressure stabilise which indicate the all the air particles inside the furnace were removed and the valve was tight prior to pyrolysis process. The pyrolysis process was conducted at $800^{\circ} \mathrm{C}$ for $20 \mathrm{~min}$. After being cooled to room temperature, the produced iron oxide magnetic biochar (MBF) was washed repeatedly with deionised water to remove impurities and to achieve $\mathrm{pH}$ 7.0.

\subsection{Characterization of magnetic biochar}

The structural pores of MBF produced at optimised condition were determined by using nitrogen adsorption at $77 \mathrm{~K}$ and degassed the sample at $200^{\circ} \mathrm{C}$ for $10 \mathrm{~h}$ by opting Autosorb 1 surface area analyser. The surface morphology and metal ion binding were determined using Field-emission scanning electron microscopy (FESEM) (Brand: Zeiss Model: Auriga). The chemical characterisation of the functional groups formed as the results of $\mathrm{HNO}_{3}$ and $\mathrm{KMnO}_{4}$ aqueous solutions introduction on the surface of biomass believe to be surface pores enhancer. The functional groups form on the surface of MBF as the product of pyrolysis was analysed by using the Fourier Transform Infrared (FTIR) (Brand: Bruker, Model: IFS66 v/S) spectroscope. Besides, the crystallinity of MBF was investigated by performing X-Ray Diffractometry (XRD) (Brand: Shimadzu) analysis and the elemental chemical composition was determined using Energy Dispersive X-Ray (EDX) spectroscope. 


\subsection{Batch sorption study of $M B F$}

Several adsorption experiments were done in the effort of identifying the effect of operational parameters to ease the adsorption capacity of the produced MBF. All adsorption experiments were carried out in $250 \mathrm{~mL}$ Erlenmeyer flask. by adding $0.3 \mathrm{~g}$ of MBF was added with $100 \mathrm{~mL}$ of $50 \mathrm{mg} / \mathrm{L}$ concentrated methylene blue dye and Cd (II) aqueous solutions were prepared respectively. The initial concentration of the adsorbate and the adsorbent dosage were fixed throughout the batch experiments. The batch adsorption study of removal of both adsorbate were carried out separately to understand the adsorption capacity of different pollutants onto MBF. The determination of factors affecting batch adsorption process was investigated by manipulating the agitation speed between $50 \mathrm{rpm}-200 \mathrm{rpm}$ and contact time between $10 \mathrm{~min}-90 \mathrm{~min}$. The adsorbate behaviour was examined by altering the $\mathrm{pH}$ value from acidic to the alkaline condition by adding $0.1 \mathrm{M} \mathrm{HCl}$ and $0.1 \mathrm{M} \mathrm{NaOH}$ to the adsorption medium. The removal percentage of adsorbates were computed using Eq. (1) below:

Removal Percentage $(\%)=\frac{C_{0}-C_{f}}{C_{o}} \times 100 \%$

where $C_{o}$ and $C_{f}$ represent the initial and final concentrations (mg/ $\mathrm{L}$ ) of adsorbate respectively. The sorption equilibrium studies at given time, $\mathrm{q}_{\mathrm{t}}$ was calculated by using Eq. (2) as stated below:

Adsorption capacity at equilibrium, $q_{e}=\frac{\left(C_{0}-C_{e}\right)}{W} V$

where $C_{o}$ and $C_{e}$ are the initial and equilibrium concentrations $(\mathrm{mg} / \mathrm{L})$ of both adsorbate respectively; $\mathrm{W}$ is the mass $(\mathrm{g})$ of MBF and $\mathrm{V}$ represent the volume $(\mathrm{L})$ of adsorbate. The removal percentage of methylene blue dye was measured by using Ultraviolet-Visible Spectrophotometry (Model: Shimadzu, UV-1800) at wavelength of $668 \mathrm{~nm}$ and Atomic Adsorption Spectroscopy (AAS) (Model: Perkin Elmer, AAnalyst 200) was used to determine the concentration of $\mathrm{Cd}$ (II) ions in aqueous solution before and after adsorption studies.

\section{Results and discussion}

\subsection{Characterisation of $M B F$}

The nitrogen adsorption-desorption isotherm at $77 \mathrm{~K}$ was performed to analyse the total surface area of both raw biomass and MBF by employing BET (Brand: Quanta Chrome Model: Autosorb 6B). The result obtained proved that pyrolysis process enhances the BET surface area and pore size as mentioned by other researchers. The great jump in total surface of MBF from $33.4 \mathrm{~m}^{2} \mathrm{~g}^{-1}$ to $831.5 \mathrm{~m}^{2} / \mathrm{g}$ as compared to ground mangosteen

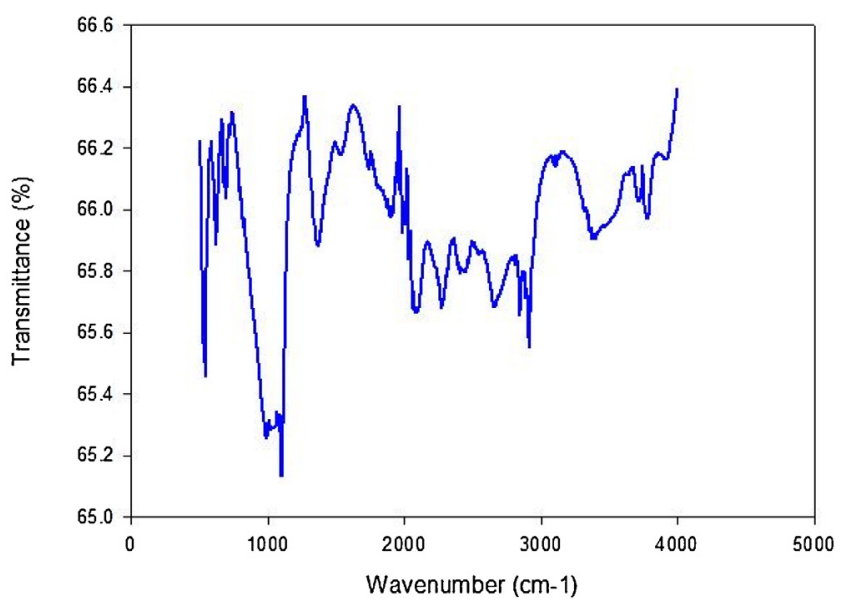

Fig. 1. FTIR analysis of MBF.

peel were due to the development of surface pores size from macropores to mesopores. The effect of sonication by introducing of $\mathrm{KMnO}_{4}$ and $\mathrm{HNO}_{3}$ aqueous solution contribute much for surface structure alteration. Furthermore, the presence of $\mathrm{Fe}^{3+}$ ions on the adsorbent surface act as a catalyst to widen the pores size besides contributing to the magnetic effect. The results obtained from this study has strongly attribute that MBF produced at vacuum condition able to increase the BET surface compared with magnetic biochar synthesised under $\mathrm{N}_{2}$ gas flow as stated by another researcher in his work [19].

The surface chemical modification took place through pyrolysis process and sonication process was determined using FTIR analysis. Fig. 1 represents the FTIR plot at a wavelength between $500 \mathrm{~cm}^{-1}-3900 \mathrm{~cm}^{-1}$ and various peaks were observed between this range. The functioning groups were determined based on the interpretation of the infrared spectrum obtained by comparing it with the standard spectrum group frequencies. MBF is having a maximum number of pores and the high peak at $500-550 \mathrm{~cm}^{-1}$, which finally confirms the presence of iron particles on the surface of the magnetic biochar [20,21]. Besides that, the broad peak around 2970 and $2932 \mathrm{~cm}^{-1}$ can be assigned to the $\mathrm{C}-\mathrm{H}$ stretching of non-ionic carboxylic groups, while peaks at $1700 \mathrm{~cm}^{-1}$ corresponds to the asymmetric and symmetric stretching vibration of $\mathrm{C}=\mathrm{O}$ bond in ionic carboxylic groups of - $\mathrm{COO}-$, respectively, showing the formation of functional groups on the surface as the effect pyrolysis [22].

The surface morphology of the produced MBF was further examined by employing FESEM. The surface scanning at different magnification scale reveals the surface topography with a large (a)

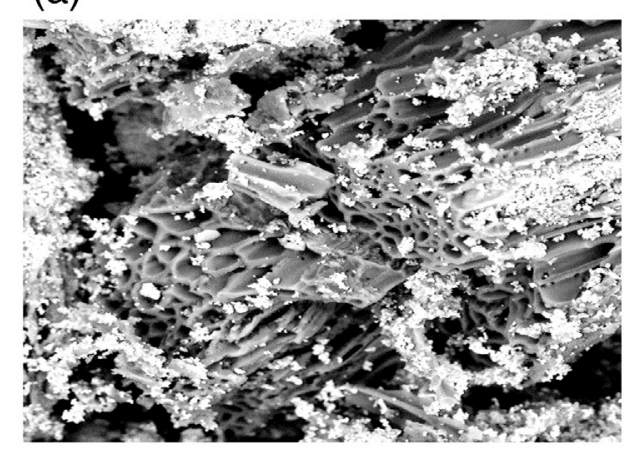

(b)

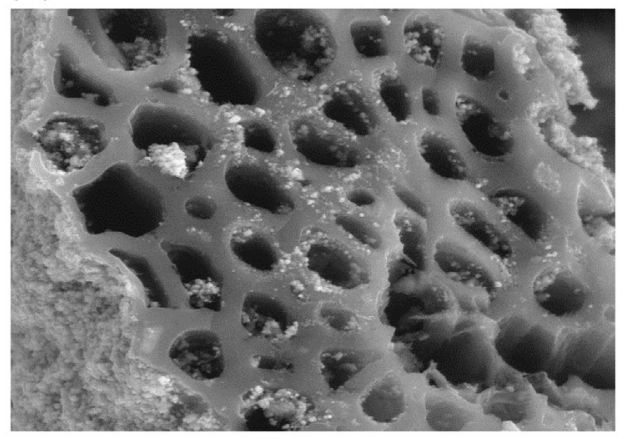

Fig. 2. FESEM image of MBF (a) $50 \mu \mathrm{m}$ and (b) $1 \mu \mathrm{m}$. 
Table 1

EDX elemental analysis of MBF.

\begin{tabular}{lll}
\hline Element & Mangosteen & MBF \\
\hline $\mathrm{C}$ & 57.79 & 68.44 \\
$\mathrm{O}$ & 40.06 & 18.38 \\
$\mathrm{Fe}$ & - & 8.78 \\
$\mathrm{~K}$ & 1.41 & 3.27 \\
$\mathrm{Mn}$ & - & 1.13 \\
$\mathrm{Al}$ & 0.74 & - \\
\hline
\end{tabular}

number of mesopores. The formation of these pores contributes much in enhancing the liquid-solid adsorption processes. The formations of pores occur due to chemical decomposition of water and other organic substances which fall down the synthesis yield [23]. The oxidation process by addition of $\mathrm{KMnO}_{4}$ and $\mathrm{HNO}_{3}$ lead to the destruction of surface micropores and lead to an extensive widening of the pores breaking of pore wall and destroying of pore structure, leading to an increase of surface area [24]. Based on the observation, it clearly states that presence of acid and alkaline substance during the preparation of precursor for the synthesis of magnetic biochar enhances the development of pores. The formation of white particles on the surface of produced magnetic biochar as shown in Fig. 2(a) and (b) confirmed the attachment of $\mathrm{Fe}^{3+}$ ions on the surface of MBF [25].

The surface elemental composition for both raw biomass and MBF were calculated via EDX analysis as shown in Table 1 . The deterioration in oxygen content and increase in carbon content on MBF compared with mangosteen peel explains the pyrolysis process convert the high cellulosic content into solid carbon in char form. The analysis shows that at higher temperatures porosity increases due to the transformation of aliphatic $C$ structures to aromatic $C$ structures Thus, iron oxide functionalisation was successfully achieved by EDX analysis [26].

Fig. 3 exhibit the XRD analysis to investigate the crystallinity of magnetic biochars. The characteristic X-ray diffraction pattern generated in a typical XRD analysis provides a unique "fingerprint" of the crystals present in the sample [27]. The crystallinity of MBF was determined using the $\mathrm{Cu}^{2+}$ tube at scanning angle, $2 \theta$ between $10^{\circ}$ and $80^{\circ}$ with a step $0.03^{\circ}$ and $2^{\circ} /$ min measuring time. The XRD patterns exhibit a significant range between $10^{\circ}$ to $80^{\circ} 2 \theta$, due to the presence of organic matter [28]. The operating voltage was kept at $40 \mathrm{kV}$ and current at $30 \mathrm{~mA}$ with a step $1^{\circ}$ and scanning speed of $2 \% \mathrm{~min}$.

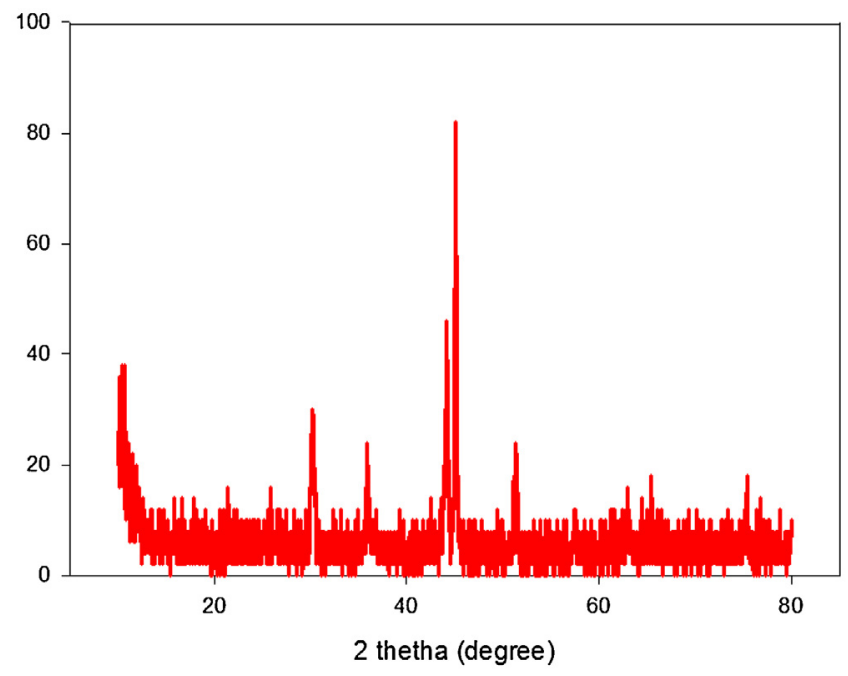

Fig. 3. XRD analysis of MBF.

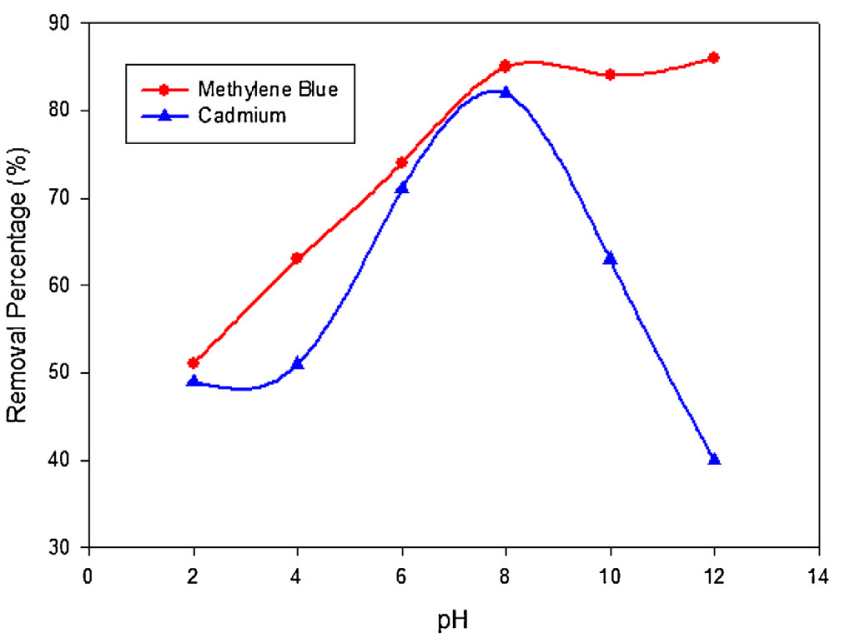

Fig. 4. Effect of pH on adsorption of (a) Methylene Blue and (b) Cd (II).

\subsection{Effect of $p H$}

$\mathrm{pH}$ is an important parameter influencing liquid pollutants adsorption from aqueous solutions. It affects both the surface charge of adsorbent and the degree of ionization of the heavy metal in solution [29]. Keeping all other parameters constant, the effect of $\mathrm{pH}$ on adsorption was made. Fig. 4 shows the effect of initial $\mathrm{pH}$ of the solution on the adsorption of Cd (II) ions and methylene blue concentration. In the present study, the $\mathrm{pH}$ was varied between 212. The plot illustrates that the removal percentage of cadmium and methylene blue increases with the change in $\mathrm{pH}$ of the solution. Removal percentage of both methylene blue and Cd (II) were $52 \%$ and $49 \%$ respectively at a $\mathrm{pH}$ value of 2.0 , which reaches a maximum value of $80 \%$ at $\mathrm{pH}$ value 7.0 . The $\mathrm{Cd}$ (II) adsorption exhibit a decreasing trend as the $\mathrm{pH}$ gradient move towards the alkaline region and result in very low adsorption percentage of $30 \%$ at the $\mathrm{pH}$ value of 12.0. At a $\mathrm{pH}$ value of 4 , removal percentage of $\mathrm{Cd}$ (II) is less i.e. $40 \%$ whereas for methylene blue it is $60 \%$. The lower adsorption at $\mathrm{pH}$ less than 6 is due to the competition between methylene and cadmium ions on the sorption sites [30]. The maximum uptake of cadmium ions occurred around $\mathrm{pH}$ 7.0, where the metals can be precipitated due to the formation of several hydroxyl low soluble species such as $\mathrm{Cd}(\mathrm{OH})_{2}$ and $\mathrm{Cd}(\mathrm{OH})^{3-}[31]$. At $\mathrm{pH}$ values higher than 8.0 insoluble cadmium hydroxide starts precipitating from the solutions making true sorption studies impossible [32,33]. The effect of $\mathrm{pH}$ onto methylene blue dye portray a better adsorption capacity at $\mathrm{pH}$ above 7.0 up to 10.0 due to the presence of more number of active sites on the surface of magnetic biochar produced gives an idea of minimized the competitive adsorption of $\mathrm{H}^{+}$and methylene blue ions resulting in no effect of $\mathrm{pH}$ at low initial concentrations due to electrostatic interaction between adsorbate and adsorbent [34,35].

\subsection{Effect of contact time}

The effect of time on the sorption process is investigated to determine the rate at which sorption takes place and the equilibrium time. The kinetics of metal sorption governs the rate, which determines the residence time, and it is one of the important characteristics defining the efficiency of an adsorbent [36]. Keeping all other parameters constant such as $\mathrm{pH}$, MBF dosage, the effect of time on adsorption was made. The result of the effect of time on the removal of cadmium and methylene blue ions by were presented in Fig. 5. As observed, a rapid increase in 


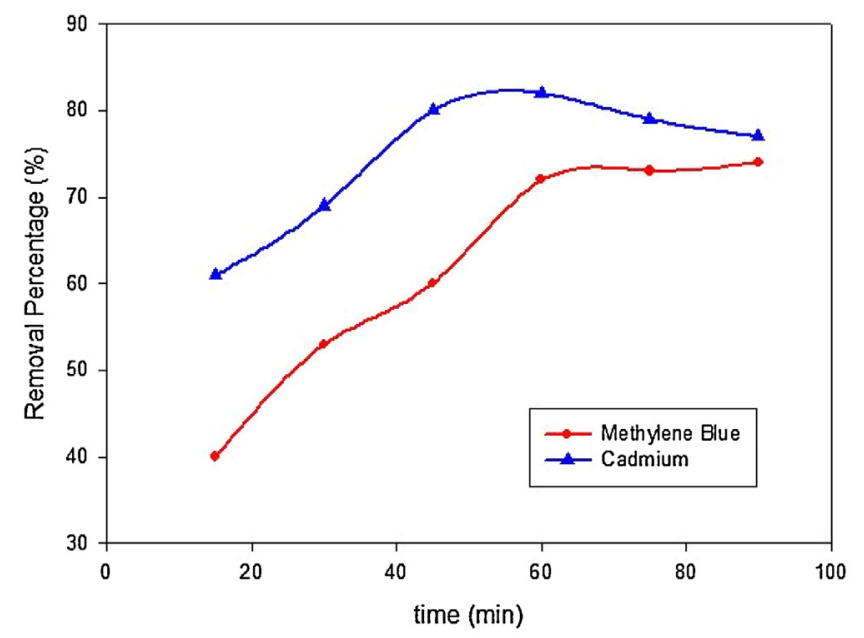

Fig. 5. Effect of agitation time on adsorption of (a) Methylene Blue and (b) Cd (II).

adsorption with an increase in time was obtained within the first $30 \mathrm{~min}$ after which the rate of adsorption became slower up to $45 \mathrm{~min}$. After $45 \mathrm{~min}$, there was no significant change in the rate of adsorption up to $120 \mathrm{~min}$ which showed that equilibrium was attained. Sorption experiments were conducted at a contact time of $90 \mathrm{~min}$ to ensure equilibrium attainment. The fast uptake capacity obtained at the initial stage due to the increased availability of the number of active binding sites on the adsorbent surface. Then enhancement in the adsorption capacity is due to the chemical interaction between adsorbates and adsorbent, a creation of some new adsorption sites or the increased rate of intra-particle diffusion of methylene blue molecules and Cd (II) ions respectively into the pores of the magnetic biochar produced. The slow and insignificant adsorption observed as time progresses is due to the fact that every adsorbent has a limited number of active sites which becomes occupied with time [37]. The difference in adsorption capacity across time of both liquid pollutants studied in this research work was due to the presence of an active site on the adsorbent surface to interact with pollutant to form chemical bonding. Cd (II) ion possesses cationic charges has steep adsorption gradient at beginning compared with methylene blue dye due to the presence of the abundance of negatively charged functional groups which exhibits greater adsorption rate. The metal ion attachment on the surface of the biochar produced evident a benchmark that magnetic biochar is an efficient adsorbent for removal of both positively and negatively charged pollutants via surface adsorption technology. Even though the adsorption capacity of methylene blue dye shows a lower adsorption gradient, process optimisation can promise an efficient adsorption trait of this fascinating adsorbent.

\subsection{Effect of agitation speed}

The effect of biosorption of MBF onto methylene blue and Cd (II) was studied at different agitation speeds. Optimum agitation speed is essential for an effective dispersion of adsorbent in adsorbate to ease the maximum adsorption capacity and formation of the external boundary film. Besides, either too low or high agitation will disrupt the physisorption of adsorbent. Fig. 6 shows the effect of agitation speed when varied from $50 \mathrm{rpm}$ to $200 \mathrm{rpm}$ with speed interval of $25 \mathrm{rpm}$ keeping all other parameters as constant. The plot shows an increase in removal percentage of methylene blue and Cd (II) with an increase in agitation speed. The amount adsorbed at equilibrium was found to increase from 50\% to $85 \%$

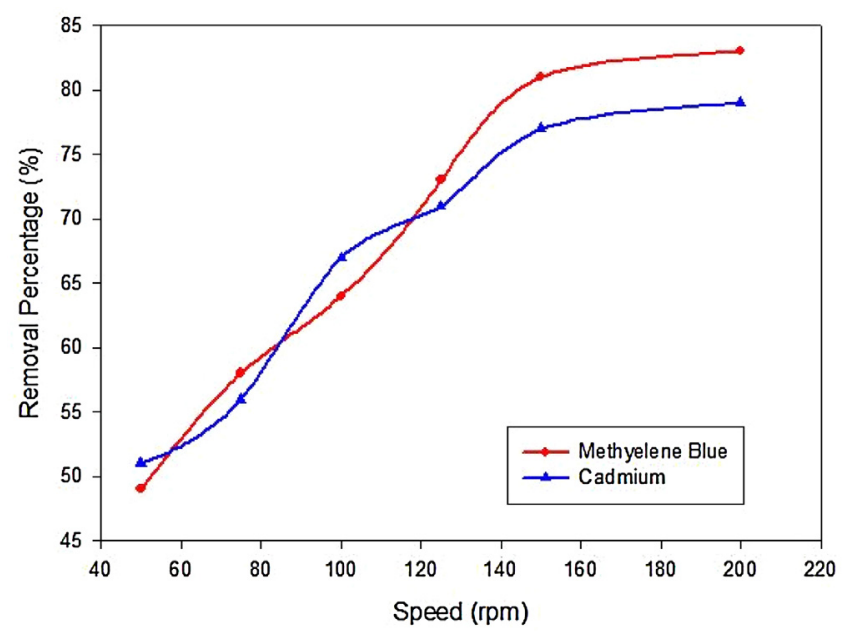

Fig. 6. Effect of agitation speed on adsorption of (a) Methylene Blue and (b) Cd (II).

with increased in agitation speed from 40 to $180 \mathrm{rpm}$. For example, at $180 \mathrm{rpm}$, removal percentage of methylene blue is $75 \%$ whereas it is $85 \%$ for Cd (II). Moreover, the both plots in Fig. 6 show low gradient value as the speed increase from $150 \mathrm{rpm}$ to $180 \mathrm{rpm}$. Hence, agitation speed above $150 \mathrm{rpm}$ gives least contribution towards adsorbate-adsorbent interaction. As the agitation speed increases, the frequency of collision also increases and hence increasing the interactions between surface functional groups on the adsorbent and the heavy metal ions. So, as the frequency increases, more molecules interact with each other and lead to a higher adsorption capacity, and eventually the removal percentage of both the Cd (II) and methylene blue increases.

This happens due to the higher interaction time between the adsorbent surface ions and the heavy metal ions. With agitation, the external mass transfer coefficient increases resulting in quicker adsorption of the liquid pollutants. This is because with low agitation speed the greater contact time is required to attend the equilibrium. With increasing the agitation speed, the rate of diffusion of dye molecules from bulk liquid to the liquid boundary layer surrounding the particle become higher because of an enhancement of turbulence and a decrease of the thickness of the liquid boundary layer.

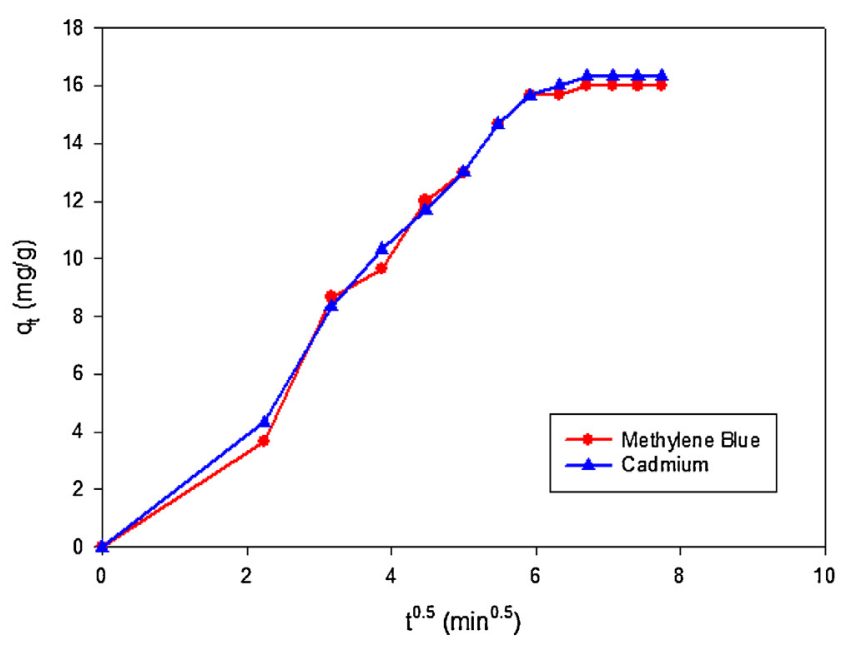

Fig. 7. Intraparticle diffusion of methylene blue dye and Cd (II). 
Table 2

Intraparticle diffusion parameters for adsorption of methylene blue dye and Cd (II).

\begin{tabular}{llll}
\hline Adsorbate & $\mathrm{K}_{\text {in }}\left(\mathrm{mg} \mathrm{g}^{-1} \mathrm{~min}^{-1 / 2}\right)$ & $\mathrm{C}_{i}\left(\mathrm{mgg}^{-1}\right)$ & $\mathrm{R}^{2}$ \\
\hline Methylene Blue & 2.248 & 0.771 & 0.936 \\
Cadmium & 2.273 & 0.822 & 0.952 \\
\hline
\end{tabular}

\subsection{Adsorption mechanism}

The Weber-Morris plot as shown in Fig. 7 exhibit the intraparticles diffusion in determining the adsorption behaviour of adsorbent-adsorbate. The Fick's second diffusion law derived from analysing the kinetic data [38] as shown in Eq. (3) below:

$q_{t}=K_{p i} t^{0.5}+C_{i}$

where $\mathrm{K}_{\mathrm{pi}}$ is the diffusion rate constant and $\mathrm{C}_{\mathrm{i}}$ gives an idea about the thickness of the boundary layer. The plot $\mathrm{q}_{\mathrm{t}}$ versus $\mathrm{t}^{0.5}$ display a linear plot if the intra-particle diffusion takes place and this mechanism is the sole rate-limiting step if the plot passes through the origin [39]. The analysis of the plot reveals that at the first, steep slope of the plot for both adsorbates studied, the diffusion of adsorbate took place through the solution to the external surface of the adsorbent. The rate-limiting factor of the sorption study was attributed to the gradual layer adsorption stage and the third stage where the adsorption process attains equilibrium due to extremely low adsorbate concentrations left in the solution. Furthermore, the slope linearity of the second and third region did not pass through the origin indicate that mass transfer deviation occurred at both initial stage and final stage of adsorption [40]. The calculated intraparticle diffusion data were shown Table 2.

\subsection{Adsorption isotherm study}

In broad, the adsorption isotherm studies explains an invaluable curve describing the phenomenon prevailing the retention or mobility of a substance from the aqueous porous media to a solidphase at a constant temperature and $\mathrm{pH}[41,42]$. The accuracy of isotherm model can be described as a function of the number of independent parameters, while its popularity in relation to the process application is an indicative of its mathematical simplicity [26]. The Langmuir and Freundlich models are used in determining the mechanism of adsorption isotherms and adsorption kinetics of both Cd (II) ions and methylene blue dye respectively onto MBF. The formation of adsorption layers onto adsorbent surface can be explained based on the presence of active site with different

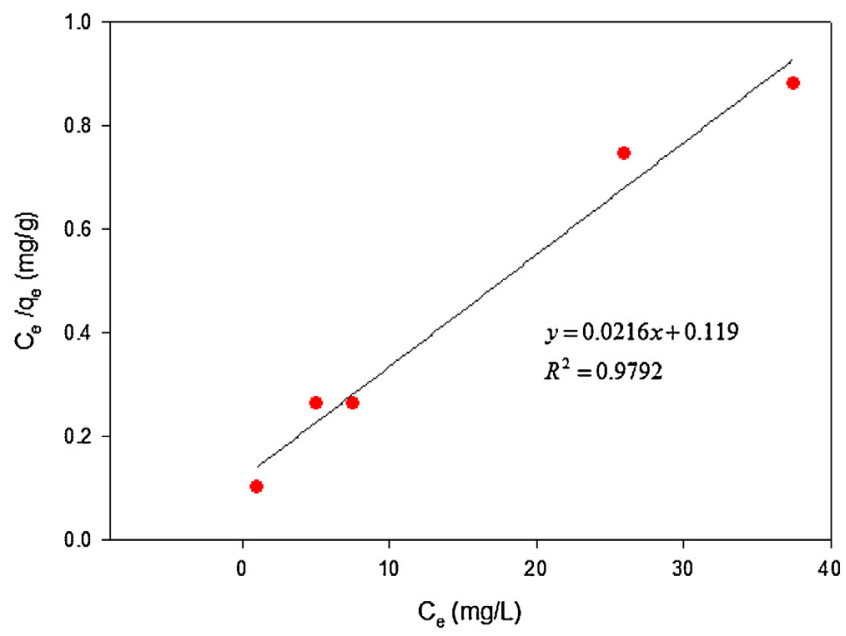

Fig. 8. Langmuir adsorption isotherm of methylene blue dye using MBF.
Table 3

Langmuir and Freundlich constant.

\begin{tabular}{|c|c|c|c|c|c|c|}
\hline \multirow[t]{2}{*}{ Adsorbate } & \multicolumn{3}{|c|}{ Langmuir Isotherm } & \multicolumn{3}{|c|}{ Freundlich Isotherm } \\
\hline & $\mathrm{K}_{\mathrm{L}}\left(\mathrm{L} \mathrm{mg}^{-1}\right)$ & $\begin{array}{l}\mathrm{q}_{\mathrm{m}} \\
\left(\mathrm{mgg}^{-1}\right)\end{array}$ & $\mathrm{R}^{2}$ & $\begin{array}{l}\mathrm{K}_{\mathrm{F}} \\
\left(\mathrm{L} \mathrm{mg}^{-1}\right)\end{array}$ & $1 / \mathrm{n}$ & $\mathrm{R}^{2}$ \\
\hline Methylene Blue & 0.182 & 46.296 & 0.979 & 2.607 & 0.394 & 0.958 \\
\hline Cd (II) & 0.091 & 45.662 & 0.994 & 2.321 & 0.446 & 0.986 \\
\hline
\end{tabular}

intensity may cause differences in the energy level of the active site available in factor of functional group formation due to effect of surface deterioration during pyrolysis process. Surface functional groups with greater energy level tend to form multilayer coverage with strong chemical bonding whilst active sites with lower energy level will induce monolayer adsorption coverage due to its electrostatic forces. The Langmuir adsorption isotherm model is commonly related to monolayer adsorption that is the adsorbed layer is one molecule in thickness. The active sites for adsorption are assumed to occur at a fixed number of definitely localized sites and are identical and equivalent [43]. In its derivation, Langmuir isotherm refers to homogeneous adsorption in which each molecule possess fixed enthalpy and activation energy, with no possibility of transmigration of the adsorbate in the plane of the surface expressed in Eq. (4) below:

$\frac{C_{e}}{q_{e}}=\frac{1}{K_{L} q_{m}}+\frac{C_{e}}{q_{m}}$

where $\mathrm{C}_{\mathrm{e}}\left(\mathrm{mg} \cdot \mathrm{L}^{-1}\right)$ and $\mathrm{q}_{\mathrm{e}}\left(\mathrm{mg} \mathrm{g}^{-1}\right)$ are the amount of unabsorbed adsorbate concentration in the solution at equilibrium concentration and adsorbed concentration of adsorbate per unit weigh of adsorbent, $\mathrm{K}_{\mathrm{L}}\left(\mathrm{L} \mathrm{mg}^{-1}\right)$ is the equilibrium constant or Langmuir constant related to the affinity of binding sites and $\mathrm{q}_{\mathrm{m}}\left(\mathrm{mg} \mathrm{g}^{-1}\right)$ represents a particle limiting adsorption capacity. The $\mathrm{K}_{\mathrm{L}}$ and $\mathrm{q}_{\mathrm{m}}$ values were calculated from the interpretation of slop and intercept of straight line $C_{e} / q_{e}$ versus $C_{e}$ as shown Fig. 8 and 9 respectively for both methylene blue dye and $\mathrm{Cd}$ (II) ions. The computed values for both adsorbate were demonstrate in Table 3 . It is observed that, the Langmuir isotherm model fit well with correlation $\mathrm{R}^{2}$ value of 0.979 and 0.994 for both methylene blue dye and Cd (II) ions respectively. Moreover, the $\mathrm{K}_{\mathrm{L}}$ and $\mathrm{q}_{\mathrm{m}}$ values were interpreted from the plot and were found to be $0.1815 \mathrm{~L} \mathrm{mg}^{-1}$ and $46.296 \mathrm{mg} \mathrm{g}^{-1}$ for methylene blue and $0.0913 \mathrm{~L} \mathrm{mg}^{-1}$ and $45.662 \mathrm{mg}$ $\mathrm{g}^{-1}$ for Cd (II) ions (Fig. 9).

In contrast to the Langmuir model, Freundlich model gives an idea that the adsorbent surface is heterogeneous and the binding

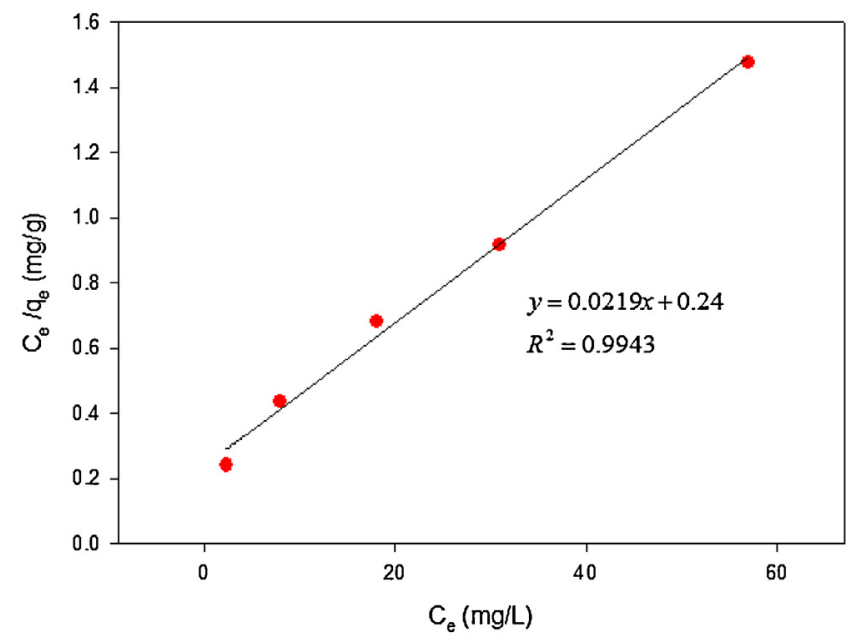

Fig. 9. Langmuir adsorption isotherm of Cd (II) ions using MBF. 
Table 4

Brief summary of application of magnetic biochar in removal of Cd (II) ion from aqueous solution.

\begin{tabular}{|c|c|c|c|c|c|c|c|c|c|c|}
\hline \multirow{2}{*}{$\begin{array}{l}\text { Initial } \\
\text { concentration }\end{array}$} & \multirow[t]{2}{*}{ Adsorbent } & \multirow{2}{*}{$\begin{array}{l}\text { Optimum } \\
\text { parameter }\end{array}$} & \multirow{2}{*}{$\begin{array}{l}\text { Removal } \\
\text { percentage }\end{array}$} & \multicolumn{3}{|c|}{ Langmuir Isotherm } & \multicolumn{3}{|c|}{ Freundlich Isotherm } & \multirow[t]{2}{*}{ References } \\
\hline & & & & $\begin{array}{l}\mathrm{q}_{\mathrm{m}} \\
\left(\mathrm{mg} \cdot \mathrm{g}^{-1}\right)\end{array}$ & $\begin{array}{l}\mathrm{K}_{\mathrm{L}} \\
\left(\mathrm{Lmg}^{-1}\right)\end{array}$ & $\mathrm{R}^{2}$ & $\begin{array}{l}\mathrm{K}_{\mathrm{F}} \\
\left(\mathrm{Lg}^{-1}\right)\end{array}$ & $1 / \mathrm{n}$ & $\mathrm{R}^{2}$ & \\
\hline $50 \mathrm{mg} \mathrm{L}^{-1}$ & MBF & $\begin{array}{l}\mathrm{pH}: 7.0 \text {, } \\
\text { speed: } \\
150 \mathrm{rpm} \text {, } \\
\text { time: } 45 \mathrm{~min} \text {, } \\
\text { dosage: } 0.3 \mathrm{~g}\end{array}$ & $97 \%$ & 45.662 & 0.091 & 0.994 & 2.321 & 0.446 & 0.986 & This Study \\
\hline $20 \mathrm{mg} \mathrm{L}^{-1}$ & $\begin{array}{l}\text { Iron oxide } \\
\text { tangerine } \\
\text { peel extract }\end{array}$ & $\begin{array}{l}\mathrm{pH}: 4.0, \\
\text { dosage: } 0.4 \mathrm{~g} \text {, } \\
\text { time: } 90 \mathrm{~min}\end{array}$ & $90 \%$ & 15.5 & 0.117 & 0.993 & 1.789 & 0.866 & 0.997 & [45] \\
\hline $10 \mathrm{mg} \mathrm{mL}^{-1}$ & $\begin{array}{l}\text { Magnetic } \\
\text { Biochar }\end{array}$ & $\begin{array}{l}\text { pH: } 5.0 \text {, } \\
\text { dosage } 1 \mathrm{~g} \\
\text { contact time: } \\
90 \text { min, }\end{array}$ & $82 \%$ & 62.50 & 0.098 & 0.992 & 25.304 & 0.443 & 0.999 & [5] \\
\hline $1-100 \mathrm{mg} \mathrm{L}^{-1}$ & $\begin{array}{l}\text { (a) Magnetic } \\
\text { oak wood } \\
\text { biochar } \\
\text { (b) Magnetic } \\
\text { oak bark } \\
\text { biochar }\end{array}$ & $\begin{array}{l}\text { pH: } 4-5 \\
\text { High } \\
\text { temperature } \\
\text { up to } 45^{\circ} \mathrm{C}\end{array}$ & $\begin{array}{l}99 \% \text { at } \\
25^{\circ} \mathrm{C} \text { and } \\
\text { pH } 5\end{array}$ & $\begin{array}{l}\text { (a) } 2.87 \\
\text { (b) } 7.40\end{array}$ & $\begin{array}{l}\text { (a) } 0.213 \\
\text { (b) } 1.366\end{array}$ & $\begin{array}{l}\text { (a) } 0.898 \\
\text { (b) } 0.754\end{array}$ & $\begin{array}{l}\text { (a) } 1.077 \\
\text { (b) } 3.52\end{array}$ & $\begin{array}{l}\text { (a) } 0.235 \\
\text { (b) } 0.292\end{array}$ & $\begin{array}{l}\text { (a) } 0.960 \\
\text { (b) } 0.779\end{array}$ & [46] \\
\hline $\begin{array}{l}\text { Not } \\
\text { mentioned }\end{array}$ & $\begin{array}{l}\text { Magnetic } \\
\text { biochar } \\
\text { composite } \\
\text { (pine bark } \\
\text { waste) }\end{array}$ & $\begin{array}{l}\mathrm{pH}: 5, \text { time, } \\
120 \text { min }\end{array}$ & $>80 \%$ & 14.96 & 1.726 & 0.924 & 8.867 & 0.187 & 0.928 & [47] \\
\hline $\begin{array}{l}10- \\
200 \mathrm{mg} \mathrm{L}^{-1}\end{array}$ & $\begin{array}{l}\text { Sawdust of } \\
\text { walnut }\end{array}$ & $\begin{array}{l}\text { Dosage: } 2 \mathrm{~g} \text {, } \\
\text { time: } 60 \mathrm{~min} \text {, } \\
\text { temperature: } \\
25^{\circ} \mathrm{C}\end{array}$ & $48.5 \%$ & 5.76 & 0.03 & 0.9895 & 0.24 & 0.667 & 0.9498 & [48] \\
\hline
\end{tabular}

sites are occupied first and then the binding strength decreases with the increasing degree of site occupation. The Freundlich adsorption isotherm model is expressed in Eq. (5) (Table 4):

$q_{e}=K_{F} C_{e}^{\frac{1}{n}}$

Where $\mathrm{K}_{\mathrm{F}}\left(\mathrm{mg} \mathrm{L}^{-1}\right)$ is defined as the adsorbents adsorption capacity and the dimensionless value of $1 / \mathrm{n}$, which ranges between zero to one exhibit the adsorption intensity or surface heterogeneity. The $K_{\mathrm{F}}$ and $1 / \mathrm{n}$ values were calculated from the slope and intercept of the linear plot of $\log q_{e}$ versus $\log C_{e}$ as exhibited in Fig. 10 for adsorption of methylene blue and Figure for Cd (II) adsorption onto $\mathrm{MBF}$ respectively. The $\mathrm{K}_{\mathrm{F}}$ and $1 / \mathrm{n}$ value for methylene blue removal from aqueous solution were determined as $2.607 \mathrm{~L} \mathrm{mg}^{-1}$ and 0.394 while adsorption of $\mathrm{Cd}$ (II) projected the calculated value of $2.321 \mathrm{~L} \mathrm{mg}^{-1}$ and 0.446 . The Freundlich constant $1 / \mathrm{n}$ below one for both adsorbents indicates it is normal adsorption. The function has an asymptotic maximum as pressure increases without bound [44]. Moreover, the higher the value of $1 / \mathrm{n}$, the greater the expected heterogeneity. On the other hand, the $n$ value in between one to ten explain that this isotherm model is favourable. The correlation $\mathrm{R}^{2}$ value of more than 0.95 for both adsorbate is favourable and well fit for the Freundlich adsorption isotherm model. The computed values for both adsorbate were presented in Table 3 (Fig. 11).

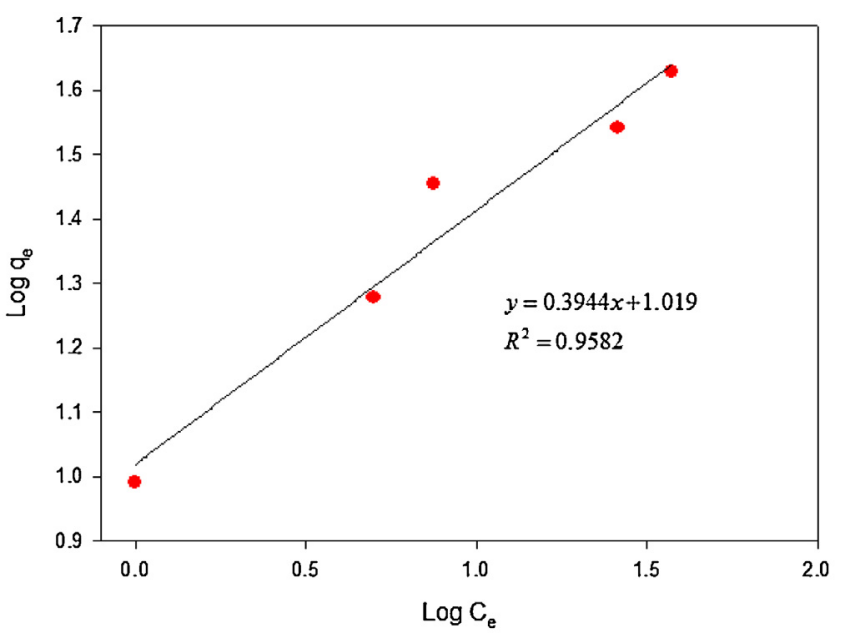

Fig. 10. Freundlich adsorption isotherm of methylene blue dye using MBF.

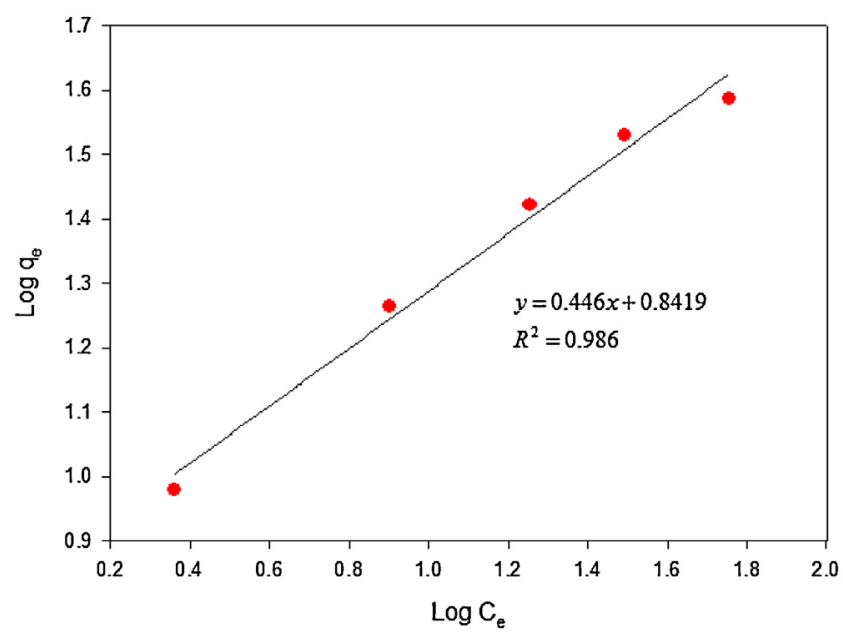

Fig. 11. Freundlich adsorption isotherm of Cd (II) ions using MBF. 
Table 5

Brief summary of application of magnetic biochar in removal of methylene blue dye from aqueous solution.

\begin{tabular}{|c|c|c|c|c|c|c|c|c|c|c|}
\hline \multirow{2}{*}{$\begin{array}{l}\text { Initial } \\
\text { concentration }\end{array}$} & \multirow[t]{2}{*}{ Adsorbent } & \multirow[t]{2}{*}{ Optimum parameter } & \multirow{2}{*}{$\begin{array}{l}\text { Removal } \\
\text { percentage }\end{array}$} & \multicolumn{3}{|c|}{ Langmuir Isotherm } & \multicolumn{3}{|c|}{ Freundlich Isotherm } & \multirow[t]{2}{*}{ References } \\
\hline & & & & $\begin{array}{l}\mathrm{q}_{\mathrm{m}} \\
\left(\mathrm{mg} \cdot \mathrm{g}^{-1}\right)\end{array}$ & $\begin{array}{l}\mathrm{K}_{\mathrm{L}} \\
\left(\mathrm{L} \mathrm{mg}^{-1}\right)\end{array}$ & $\mathrm{R}^{2}$ & $\begin{array}{l}\mathrm{K}_{\mathrm{F}} \\
\left(\mathrm{Lg}^{-1}\right)\end{array}$ & $1 / \mathrm{n}$ & $\mathrm{R}^{2}$ & \\
\hline $50 \mathrm{mg} \mathrm{L}^{-1}$ & MBF & $\begin{array}{l}\text { pH: } 7.0 \text {, speed: } 150 \mathrm{rpm} \text {, time: } 50 \mathrm{~min} \text {, } \\
\text { dosage: } 0.3 \mathrm{~g}\end{array}$ & $95 \%$ & 46.296 & 0.182 & 0.979 & 2.607 & 0.394 & 0.958 & This Study \\
\hline $\begin{array}{l}250- \\
750 \mathrm{mg} \mathrm{L}^{-1}\end{array}$ & $\begin{array}{l}\text { Posidonia oceanica } \\
\text { activated carbon }\end{array}$ & $\begin{array}{l}\text { Time: } 60 \text { min,Dosage: } 0.05 \text { g, pH: 6.5, Speed: } \\
130 \mathrm{rpm}\end{array}$ & $\begin{array}{l}\text { Not } \\
\text { mentioned }\end{array}$ & 217.39 & 1.7 & 0.990 & 112.12 & 0.365 & 0.918 & [49] \\
\hline $100 \mathrm{mg} \mathrm{L}^{-1}$ & $\begin{array}{l}\text { C. barbatula Kützing } \\
\text { seaweed }\end{array}$ & $\begin{array}{l}\text { Time: } 210 \mathrm{~min} \text {, Dosage: } 0.1 \mathrm{~g}, \mathrm{pH}: 7-10 \text {, } \\
\text { Speed: } 215 \mathrm{rpm} \text {, Temperature: } 35^{\circ} \mathrm{C}\end{array}$ & $99 \%$ & 21.929 & 2.5910 & 0.9935 & 39.884 & 0.827 & 0.9875 & [35] \\
\hline $\begin{array}{l}50- \\
300 \mathrm{mg} \mathrm{L}^{-1}\end{array}$ & $\begin{array}{l}\text { Magnetic } \\
\mathrm{Ni0} \cdot 5 \mathrm{ZnO} 0 \cdot 5 \mathrm{Fe}_{2} \mathrm{O}_{4} \\
\text { nanoparticles }\end{array}$ & $\begin{array}{l}\text { Time: } 30 \text { min, Dosage: } 0.05 \mathrm{~g}, \mathrm{pH}: 3 \text {, Speed: } \\
130 \mathrm{rpm} \text {, Temperature: } 25^{\circ} \mathrm{C}\end{array}$ & $\begin{array}{l}\text { Not } \\
\text { mentioned }\end{array}$ & 54.719 & 0.741 & 0.858 & 25.456 & 0.229 & 0.989 & {$[16]$} \\
\hline $50 \mathrm{mg} \mathrm{L}^{-1}$ & Watermelon rinds & $\begin{array}{l}\text { Time: } 30 \mathrm{~min} \text {, Dosage: } 0.01 \mathrm{~g}, \mathrm{pH}: 7 \\
\text { temperature: } 30^{\circ} \mathrm{C}\end{array}$ & $85 \%$ & 243.9 & 0.04 & 0.963 & 7.41 & 0.06 & 0.870 & [34] \\
\hline $5-100 \mathrm{mg} \mathrm{L}^{-1}$ & $\begin{array}{l}\text { Invasive marine } \\
\text { seaweed }\end{array}$ & $\begin{array}{l}\text { Time: } 90 \text { min, Dosage: } 0.5 \mathrm{~g}, \mathrm{pH}: 11 \text {, speed: } \\
105 \mathrm{rpm} \text {, Temperature: } 27^{\circ} \mathrm{C}\end{array}$ & $95.5 \%$ & 3.423 & 0.797 & 0.9926 & 1.662 & 0.855 & 0.9832 & {$[50]$} \\
\hline $281.25 \mathrm{mg} \mathrm{L}^{-1}$ & $\begin{array}{l}\text { Magnetic corncob- } \\
\text { derived adsorbent }\end{array}$ & $\begin{array}{l}\text { Time: } 850 \text { min, speed: } 100 \mathrm{rpm} \text {, } \\
\text { Temperature: } 27^{\circ} \mathrm{C}\end{array}$ & $99 \%$ & 163.93 & 0.216 & 0.999 & 28.199 & 0.223 & 0.893 & [51] \\
\hline
\end{tabular}

\section{Conclusion}

Mangosteen peel derived iron oxide impregnated magnetic biochar was successfully synthesised at zero oxygen environment by employing modified electrical muffle furnace at $800^{\circ} \mathrm{C}$ heating temperature for $20 \mathrm{~min}$ heating duration. The effect of the adsorption parameters was studied and the optimised conditions for both methylene blue dye and Cd (II) ions were investigated respectively. The removal of methylene blue dye attained maximum removal at $\mathrm{pH}$ of 7.0 and above, 50 min contact time and $150 \mathrm{rpm}$ agitation speed. Moreover, adsorption equilibrium of $\mathrm{Cd}$ (II) ions reaches maximum removal percentage at the $\mathrm{pH}$ value of 7.0, agitation speed of $150 \mathrm{rpm}$ and $45 \mathrm{~min}$ contact time. The optimised adsorption parameters obtained in this study were interacted in batch adsorption study and highest removal percentage of both methylene blue dye and Cd (II) ions from aqueous solution were recorder 95\% and 97\% respectively (Table 5).

\section{Acknowledgement}

This work is fully supported by Malaysia-Japan International Institute of Technology under FRGS/2/2013/TK05/UTM/01/5.

\section{References}

[1] N. Kannan, M.M. Sundaram, Kinetics and mechanism of removal of methylene blue by adsorption on various carbons-a comparative study, Dyes Pigm. 51 (1) (2001) 25-40.

[2] L. Lin, et al., Removal of ammonia nitrogen in wastewater by microwave radiation: a pilot-scale study, J. Hazard. Mater. 168 (2) (2009) 862-867.

[3] K. Mohanty, D. Das, M. Biswas, Preparation and characterization of activated carbons from Sterculia alata nutshell by chemical activation with zinc chloride to remove phenol from wastewater, Adsorption 12 (2) (2006) 119-132.

[4] N.M. Mubarak, et al., Statistical optimization and kinetic studies on removal of Zn2+ using functionalized carbon nanotubes and magnetic biochar, J. Environ. Chem. Eng. 1 (3) (2013) 486-495.

[5] M. Ruthiraan, et al., Comparative kinetic study of functionalized carbon nanotubes and magnetic biochar for removal of $\mathrm{Cd} 2+$ ions from wastewater, Korean J. Chem. Eng. 32 (3) (2015) 446-457.

[6] N. Mubarak, et al., Statistical optimization and kinetic studies on removal of $\mathrm{Zn} 2+$ using functionalized carbon nanotubes and magnetic biochar, J. Environ. Chem. Eng. 1 (3) (2013) 486-495.

[7] J. Ruparelia, et al., Potential of carbon nanomaterials for removal of heavy metals from water, Desalination 232 (1) (2008) 145-156.

[8] Y.-H. Li, et al., Adsorption thermodynamic: kinetic and desorption studies of Pb2+ on carbon nanotubes, Water Res. 39 (4) (2005) 605-609.

[9] E. Erdem, N. Karapinar, R. Donat, The removal of heavy metal cations by natural zeolites, J. Colloid Interface Sci. 280 (2) (2004) 309-314.

[10] Y.-H. Li, et al., Lead adsorption on carbon nanotubes, Chem. Phys. Lett. 357 (34) (2002) 263-266.
[11] S. Acharya, F. Dilnawaz, S.K. Sahoo, Targeted epidermal growth factor receptor nanoparticle bioconjugates for breast cancer therapy, Biomaterials 30 (29) (2009) 5737-5750.

[12] N. Abdel-Ghani, G. Elchaghaby, Influence of operating conditions on the removal of $\mathrm{Cu}, \mathrm{Zn} \mathrm{Cd}$ and $\mathrm{Pb}$ ions from wastewater by adsorption, Int. J. Environ. Sci. Technol. 4 (4) (2007) 451-456.

[13] K. Mohanty, et al., Preparation and characterization of activated carbons from terminalia arjuna nut with zinc chloride activation for the removal of phenol from wastewater, Ind. Eng. Chem. Res. 44 (11) (2005) 4128-4138.

[14] F.D. Ardejani, et al., Numerical modelling and laboratory studies on the removal of Direct Red 23 and Direct Red 80 dyes from textile effluents using orange peel: a low-cost adsorbent, Dyes Pigm. 73 (2) (2007) 178-185.

[15] C. Moreno-Castilla, Adsorption of organic molecules from aqueous solutions on carbon materials, Carbon 42 (1) (2004) 83-94.

[16] L. Ruijiang, et al., Adsorption Characteristics of Methyl Blue onto Magnetic $\mathrm{Ni0} .5 \mathrm{Zn0.5} \mathrm{Fe}_{2} \mathrm{O}_{4}$ Nanoparticles Prepared by the Rapid Combustion Process, INIS, 2013.

[17] K.R. Thines, et al., Synthesis of magnetic biochar from agricultural waste biomass to enhancing route for waste water and polymer application: a review, Renew. Sustain. Energy Rev. 67 (2017) 257-276.

[18] Y. Chen, et al., Adsorption of Cu (II) from aqueous solution using activated carbon derived from mangosteen peel, BioResources 7 (4) (2012) 4965-4975.

[19] Y. Zhang-Steenwinkel, et al., Microwave-assisted in-situ regeneration of a perovskite coated diesel soot filter, Chem. Eng. Sci. 60 (3) (2005) 797-804.

[20] A.E. Pirbazari, E. Saberikhah, S.H. Kozani, $\mathrm{Fe}_{3} \mathrm{O}_{4}$-wheat straw: preparation, characterization and its application for methylene blue adsorption, Water Resour. Ind. 7 (2014) 23-37.

[21] Y. Wang, et al., Adsorption of $\mathrm{Pb}$ (II) from aqueous solution to Ni-doped bamboo charcoal, J. Ind. Eng. Chem. 19 (1) (2013) 353-359.

[22] W. Wang, et al., Cr (VI) removal from aqueous solution with bamboo charcoal chemically modified by iron and cobalt with the assistance of microwave, J. Environ. Sci. 25 (9) (2013) 1726-1735.

[23] D. Mohan, et al., Modeling and evaluation of chromium remediation from water using low cost bio-char: a green adsorbent, J. Hazard. Mater. 188 (1) (2011) 319-333.

[24] N.M. Mubarak, et al., Adsorption and kinetic study on sn2+ removal using modified carbon nanotube and magnetic biochar, Int. J. Nanosci. 12 (06) (2013) 1350044.

[25] H. Sun, et al., Multiple controls on the chemical and physical structure of biochars, Ind. Eng. Chem. Res. 51 (9) (2012) 3587-3597.

[26] K. Foo, B. Hameed, Insights into the modeling of adsorption isotherm systems, Chem. Eng. J. 156 (1) (2010) 2-10.

[27] N. Petigny, et al., In situ XRD analysis of the oxide layers formed by oxidation at $743 \mathrm{~K}$ on Zircaloy 4 and Zr-1NbO, J. Nucl. Mater. 280 (3) (2000) 318-330.

[28] X. Cao, W. Harris, Properties of dairy-manure-derived biochar pertinent to its potential use in remediation, Bioresour. Technol. 101 (14) (2010) 5222-5228.

[29] K.S. Rao, S. Anand, P. Venkateswarlu, Adsorption of cadmium (II) ions from aqueous solution by Tectona grandis LF (teak leaves powder), BioResources 5 (1) (2010) 438-454.

[30] D. Malferrari, et al., Sorption kinetics and chemical forms of Cd (II) sorbed by thiol-functionalized 2: 1 clay minerals, J. Hazard. Mater. 143 (1) (2007) 73-81.

[31] K.S. Low, C.K. Lee, S. Liew, Sorption of cadmium and lead from aqueous solutions by spent grain, Process Biochem. 36 (1) (2000) 59-64.

[32] J. Yu, et al., Cystine-modified biomass for Cd (II) and Pb (II) biosorption, J. Hazard. Mater. 143 (1) (2007) 277-284.

[33] H.-C. Yang, et al., Mechanisms and kinetics of cadmium and lead capture by calcined kaolin at high temperatures, Korean J. Chem. Eng. 18 (4) (2001) 499505. 
[34] R. Lakshmipathy, N. Sarada, Methylene blue adsorption onto native watermelon rind: batch and fixed bed column studies, Desalin. Water Treat. (2015) 1-14.

[35] D. Caparkaya, L. Cavas, Biosorption of methylene blue by a brown alga Cystoseira barbatula Kützing, Acta Chim. Slov. 55 (2008) 547-553.

[36] K.A. Krishnan, T. Anirudhan, Removal of cadmium (II) from aqueous solutions by steam-activated sulphurised carbon prepared from sugar-cane bagasse pith: kinetics and equilibrium studies, Water SA 29 (2) (2003) 147-156.

[37] M. Badmus, T. Audu, B. Anyata, Removal of lead ion from industrial wastewaters by activated carbon prepared from periwinkle shells (Typanotonus fuscatus), Turk. J. Eng. Environ. Sci. 31 (4) (2007) 251-263.

[38] W.J. Weber, J.C. Morris, Kinetics of adsorption on carbon from solution, J. Sanit. Eng. Div. 89 (2) (1963) 31-60.

[39] K. Foo, B. Hameed, Factors affecting the carbon yield and adsorption capability of the mangosteen peel activated carbon prepared by microwave assisted $\mathrm{K}_{2} \mathrm{CO}_{3}$ activation, Chem. Eng. J. 180 (2012) 66-74.

[40] F.-C. Wu, R.-L. Tseng, R.-S. Juang, Initial behavior of intraparticle diffusion model used in the description of adsorption kinetics, Chem. Eng. J. 153 (1) (2009) $1-8$

[41] G. Limousin, et al., Sorption isotherms: a review on physical bases, modeling and measurement, Appl. Geochem. 22 (2) (2007) 249-275.

[42] S. Allen, G. Mckay, J. Porter, Adsorption isotherm models for basic dye adsorption by peat in single and binary component systems, J. Colloid Interface Sci. 280 (2) (2004) 322-333.
[43] K. Vijayaraghavan, et al., Biosorption of nickel (II) ions onto Sargassum wightii: application of two-parameter and three-parameter isotherm models, J. Hazard. Mater. 133 (1) (2006) 304-308.

[44] S.V. Mohan, J. Karthikeyan, Removal of lignin and tannin colour from aqueous solution by adsorption onto activated charcoal, Environ. Pollut. 97 (1) (1997) 183-187.

[45] M.H. Ehrampoush, et al., Cadmium removal from aqueous solution by green synthesis iron oxide nanoparticles with tangerine peel extract, J. Environ. Health Sci. Eng. 13 (1) (2015) 1.

[46] D. Mohan, et al., Cadmium and lead remediation using magnetic oak wood and oak bark fast pyrolysis bio-chars, Chem. Eng. J. 236 (2014) 513-528.

[47] D. Harikishore Kumar Reddy, S.-M. Lee, Magnetic biochar composite: facile synthesis, characterization, and application for heavy metal removal, Coll. Surf. A 454 (2014) 96-103.

[48] Y. Bulut, Removal of heavy metals from aqueous solution by sawdust adsorption, J. Environ. Sci. 19 (2) (2007) 160-166.

[49] M.U. Dural, et al., Methylene blue adsorption on activated carbon prepared from Posidonia oceanica (L.) dead leaves: kinetics and equilibrium studies, Chem. Eng. J. 168 (1) (2011) 77-85.

[50] S. Cengiz, L. Cavas, Removal of methylene blue by invasive marine seaweed: caulerpa racemosa var. cylindracea, Bioresour. Technol. 99 (7) (2008) 23572363.

[51] H. Ma, et al., Novel synthesis of a versatile magnetic adsorbent derived from corncob for dye removal, Bioresour. Technol. 190 (2015) 13-20. 